\title{
EVOCACIONES DE LA ARCADIA COLONIAL EN LA LITERATURA PERUANA: DE RICARDO PALMA A JULIO RAMÓN RIBEYRO
}

\author{
EVA $M^{a}$ VALERO JUAN
}

1

Antonio Cornejo Polar, La formación de la tradición literaria en el Perú, Lima, Centro de Estudios y Publicaciones, 1989, pág. 61.
Evocaciones de la arcadia colonial en la literatura peruana: de Ricardo Palma a Julio Ramón Ribeyro
Para plantear un acercamiento a las recuperaciones del pasado en la literatura peruana es preciso advertir, en primer lugar, que dicha recuperación se concreta, fundamentalmente, en una tradición literaria urbana que tiene su origen a finales del siglo XIX en la obra de Ricardo Palma. En sus Tradiciones peruanas Palma construye la ciudad mítica de la colonia, inaugurando un discurso evocativo cuyas reminiscencias todavía se sentirán a mediados del siglo XX en la obra de escritores como Sebastián Salazar Bondy o Julio Ramón Ribeyro, quien aceptó el desafío de crear la geografía literaria de la Lima moderna. Entre Palma y Ribeyro, la historia de la capital en la literatura peruana se desarrolla a través de la tradición de "una Lima que se va", título de la obra de José Gálvez (1921) en la que el cronista, recogiendo la semilla implantada en las Tradiciones peruanas, consolida una literatura urbana basada en las recuperaciones del pasado.

Ricardo Palma destaca en la tradición literaria del Perú como creador de un género original, cuyo objetivo primordial se basa en el rescate de un pasado tanto histórico como literario y en la creación de la leyenda urbana que dota a la ciudad de la dimensión mítica de la que carecía. Palma construye este discurso desde una doble perspectiva indisoluble: por una parte, la que afecta al entramado social y al anecdotario histórico de los siglos anteriores; y por otra, la que se refiere a la recuperación concreta de la tradición literaria, es decir, la perspectiva que se formula como construcción de un intertexto. Es así como el tradicionista se ocupa en varias ocasiones de los creadores de la tradición literaria costeña: por ejemplo, dedica una «tradición» a Juan del Valle y Caviedes - «El poeta de la Ribera don Juan del Valle y Caviedes»-; cita en varias ocasiones a Concolorcorvo; hace una caracterización de Esteban de Terralla y Landa en la «tradición» «El poeta y las adivinanzas»; y, sobre todo, reconoce su deuda con Manuel Ascencio Segura, por haber instaurado el imaginario cultural del costumbrismo en «La saya y el manto», «Nadie me la pega», «Ña Catita», etc.

En este sentido, Antonio Cornejo Polar atribuye a Palma la virtud de haber conseguido crear, a través de la utilización de textos coloniales en su escritura, un auténtico intertexto, de forma que logra convertir la historia de la literatura peruana en «una secuencia viva, ininterrumpida, capaz de prolongarse hacia el futuro» ${ }^{\text {t: }}$

Palma es, entonces, el encargado de vencer la timidez histórica del costumbrismo, dotándolo del sentimiento de tradición que nunca tuvo, y por esa vía termina siendo el fundador de una conciencia bistórica que define por largo tiempo la imagen del proceso formativo de la nacionalidad. Hereda del costumbrismo, sin embargo, su capacidad elusiva y desproblematizadora [...] El abrumador triunfo de Palma tiene como base su habilidad para realizar una operación compleja sin comprometerse con todo lo que es- 
taba implícito en la restauración del vínculo histórico con la colonia ${ }^{2}$.

Al margen de la polémica sobre la visión histórica con que Palma aborda la restauración del vínculo con la colonia, parece claro que la recuperación de la literatura colonial, unida a la visión intrahistórica de los siglos anteriores, confluye como restitución de una conciencia histórica esencial para la construcción de la nueva nación. En el problemático ambiente republicano, esta afirmación de las raíces era necesaria, y de ella se deduce una mitificación de la ciudad como Arcadia, como respuesta de un momento histórico fluctuante e inestable, que buscaba referentes para salvaguardar la tambaleante utopía republicana. En este sentido, el debate sobre la actitud de Palma hacia el pasado traduce los diferentes posicionamientos ideológicos que se generan entre los siglos XIX y XX con respecto a ese pasado.

Algunos han querido destacar en las Tradiciones una imagen edulcorada de la ciudad para poder atribuirle la creación, la génesis, del mito colonialista. Otros, por el contrario, han resaltado la veta crítica, mordaz y satírica con que el escritor retrata la Lima colonial. Entre estos últimos, José Carlos Mariátegui, en sus Siete ensayos de interpretación de la realidad peruana, incidió en que la reconstrucción de la Colonia por Palma es de «un realismo burlón y una fantasía irrevenrente y satírica. La versión de Palma es cruda y viva. La de los prosistas y poetas de la serenata bajo los balcones del virreinato (...) es devota y ditirámbica». Al tiempo que acusaba al «colonialismo - evocación nostálgica del virreinatode pretender anexarse la figura de Ricardo Palma». Por ello, Mariátegui puso especial atención en dejar claro que "no hay ningún parecido sustancial, ningún parentesco psicológico entre una y otra versión» ${ }^{3}$. De esta forma, a través de Palma las diferentes ideologías ofrecen su propia visión del pasado, generando con esta instrumentalización una imagen muy disímil de las Tradiciones.

Al margen de la polémica, esta obra vivificó el pasado colonial como respuesta a la necesidad de asumir una herencia histórica y cultural que se había silenciado tras la emancipación; en definitiva, como respuesta al proceso de la independencia, pues el interés por las costumbres antiguas se encuentra ligado, fundamentalmente, a la necesidad de definir la nacionalidad, de afir- mar la identidad colectiva, $y$ la predilección por el pasado responde tanto a los postulados de la corriente romántica como a la urgencia por recuperar la conciencia histórica tras el desconcierto reinante en las primeras décadas de la emancipación. Su función no fue la de ofrecer un fiel

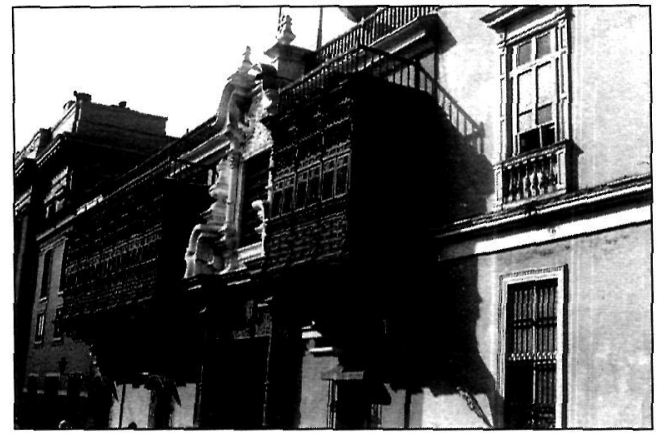

Palacio Torre Tagle (1735). Lima retrato histórico de la realidad-por lo que se le reprocha el haber dado una imagen ficticia del pasado-, sino la de satirizar ese fragmento de la sociedad que ocupa el retrato de su fábula: la sociedad limeña de la colonia en su menuda historia. En este sentido, José Miguel Oviedo comenta:

Palma rescató del olvido un pasado peruano que la historia oficial no iba a registrar; un pasado doméstico, de quisicosas: migajas de un banquete solemne. En ello residen la significación literaria y las limitaciones estéticas de su arte. Palma vivificó ese pasado y lo acercó al presente, para darle vitalidad y animación de cosa actual, plena de color y movimiento. [...] Pudo escribir la gran novela peruana del siglo XIX [...] pero se contentó con pintar estampas amablemente irónicas y delicados esmaltes coloniales; prefirió la amenidad y la brillantez inmediatas -exigencias de una literatura «popular»- a la visión honda y a la interpretación menos eventual de una sociedad que conocía muy bien. La sátira y el humor fueron una máscara fiel [...] pero también fueron un disfraz cortesano que ocultó los más dramáticos perfiles de nuestra sociedad decimonónica4.

En cualquier caso, la importancia de Palma radica en la asimilación de una herencia histórica y cultural que se había silenciado tras la emancipación, y en esa dirección encuentra una de las vías para la construcción de una literatura nacional.

Para hablar de la formación de la conciencia histórica, hay que recordar que la «secuencia viva» de la tradición peruana tiene su origen en el primer fundador de dicha conciencia, el Inca Garcilaso. Palma no dedicó muchas tradiciones al período incaico, de modo que en la globalidad de las Tradiciones el intertexto con la obra del Inca es más bien escaso. De cual-
2 Ibidem, págs. 62-63. La cursiva es nuestra.

3

José Carlos Mariátegui, Siete ensayos de inferprefación de la realidad peruana (1929), México, Era, 1979, págs. 218-219.

4

José Miguel Oviedo, Ricardo Palma, Buenos Aires, Centro Editor de América Latina, 1968, pág. 33.

Evocaciones de la arcadia colonial en la literatura peruana: de Ricardo Palma a Julio Ramón Ribeyro EVA Ma VALERO JUAN 


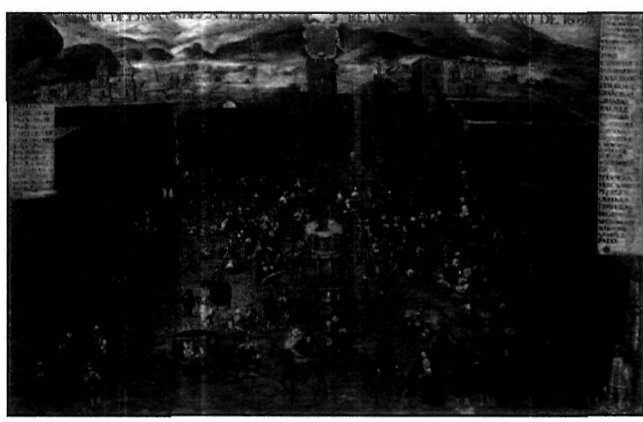

Anónimo. Plaza Mayor de Lima en 1680

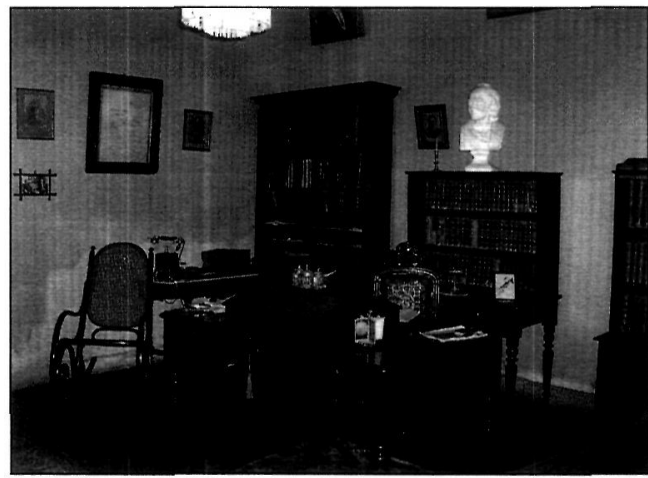

Casa Museo Ricardo Palma. Lima

5

Raúl Porras Barrenechea, El sentido tradicional de la literatura peruana, Lima, Instituto Raúl Porras Barrenechea, 1969, pág. 60.

Julio Ramón Ribeyro, "Gracias, viejo socarrón", en Antología personal, México, Fondo de Cultura Económica, 1994, págs. 129-130.

Evocaciones de la arcadia colonial en la literatura peruana: de Ricardo Palma a Julio Ramón Ribeyro EVA $\mathrm{M}^{n}$ VALERO JUAN quier modo, la mayor parte de los relatos indígenas que se encuentran en la obra de Palma provienen de los Comentarios Reales, una de las únicas fuentes que el autor poseía sobre este período. Tal vez, como plantea Porras Barrenechea, no dedicó más «tradiciones» al pasado incaico por no repetir lo que el Inca ya había narrado ${ }^{5}$ Pero el lazo de unión entre ambos autores tiene una importancia mayor que la que pueda desprenderse del proceso intertextual. Es decir, se encuentra más en la intimidad de lo narrado, que en lo superficial de los textos utilizados.

Garcilaso construyó el mestizaje cultural en la Colonia recogiendo el legado de los relatos indígenas y fundiéndolo con la herencia española. Instauró la conciencia histórica durante la Colonia, pero su recuperación del pasado es también idílica y desproblematizadora. Del mismo modo, Palma recupera el legado colonial y, pasándolo por el tamiz de una desbordada inventiva, lo transmite al espíritu republicano con el objeto de crear una nueva conciencia histórica para la nación recién constituida. Del Cuzco incaico a la Lima virreinal, un espíritu nostálgico ha rescatado el legado de la historia peruana, cuyas abisales fisuras -la Conquista y la Independencia- no consiguieron imponer el olvido ni quebrantar la especial predilección del peruano por el relato y el culto a la tradición.

El Inca Garcilaso y Ricardo Palma se complementan por tanto como fundadores de la conciencia histórica pues ambos rescatan del olvido la historia viva del Perú, respondiendo a una necesidad, no tanto de conservar un legado sino de asimilar una herencia. El debate sobre la falsificación de la historia parece por otra parte, estéril, pues lo que encontramos tanto en los Comentarios como en las Tradiciones es la historia convertida en arte, pasada por el tamiz de una desbordada inventiva, en definitiva, historia mitificada que emana de las anécdotas del cotidiano vivir.
Pero volvamos a la idea de la mitificación urbana a través de la recuperación del pasado. Ésta fue formulada por Julio Ramón Ribeyro en el artículo que dedica a Ricardo Palma, titulado «Gracias, viejo socarrón». Para Ribeyro, desde un posicionamiento ya ajeno y distanciado de la mentada polémica sobre la visión del pasado en las Tradiciones, lo que parece indiscutible es que la existencia de Lima como ciudad histórica, tal y como se concibe en el imaginario cultural, se debe a esta obra de Ricardo Palma. La polémica se diluye en las estremecidas palabras de agradecimiento con las que Ribeyro homenajea a quien considera primer fundador literario de Lima:

Las Tradiciones, tan pronto ensalzadas como criticadas. Se ha dicho mucho sobre ellas. Para unos es una obra democrática y para otros reaccionaria. Se le ha calificado también de nacional y de hispanófila, de amena y de aburrida, de retrógrada y de innovadora, de veraz y de falsa. Atizar estos debates tampoco es mi intención. Sólo quiero resaltar su función en tanto que fundadora de una memoria nacional y de una conciencia ancestral común.

Sin las Tradiciones nos sería difícil, por no decir imposible, imaginar nuestro pasado desde la Conquista hasta la Emancipación. Estaríamos huérfanos del período más próximo y significativo de nuestra historia milenaria. Ese vacío podríamos colmarlo, es cierto, pero cada cual a su manera y a costa de un esfuerzo desalentador, buscando y leyendo cientos de libros y documentos poco accesibles, áridos, mal escritos o idiotas. Ricardo Palma cumplió ese trabajo por nosotros. [...] extrajo lo que a su juicio era digno de recordarse y transmitirse. Es posible que olvidara muchas cosas, desdeñara otras e inventara una buena parte y que impregnase todo lo que tocó con su espíritu festivo, ligero y socarrón, impermeable a los aspectos más graves y dramáticos de nuestra realidad. Sabemos ahora que de los 50.000 habitantes que tenía Lima a comienzos del siglo XVII, 40.000 eran esclavos negros o servidores indígenas, de cuya vida, problemas y luchas queda poco o nada en la obra de Palma. Pero aún así, las Tradiciones son la única prueba accesible, artística y entretenida que tenemos de ese pasado. Ninguna obra anterior o de su época se le puede comparar (salvo Garcilaso para el Incario y primeros años de la Conquista). [...] Si la imagen palmiana de Lima subsiste es porque nadie ha sido capaz de desembarazarnos de ella ${ }^{6}$.

Unos años más tarde, en los albores del siglo XX, los procesos de cambio comienzan a 
acelerar las mutaciones urbanas y la derrota frente a Chile en la Guerra del Pacífico (1879) imprime su sello trágico a la abolición del pasado idílico. En el ambiente desolador de la posguerra surge una nueva generación de escritores, los llamados hijos de la Guerra del Pacífico, cuyas obras eluden la problemática nacional para ofrecernos la versión pasatista de la ciudad que comienza a experimentar el ímpetu ineludible de la modernidad. Tras la gran derrota que arruina el país, el espejismo del pasado se acrecienta, y lo que había sido en Palma recuperación vivificante y asimilación de la historia se convierte ahora en una propuesta literaria que carga sus acentos en el sentimiento de pérdida, impregnando la visión urbana de nostalgia y melancolía, y generando, de una manera muy clara, la versión idealizadora de la Arcadia colonial. Entre las obras de José Gálvez, Ventura García Calderón o Enrique A. Carrillo, entre otros, la obra más destacable en el sentido de la recuperación mitificadora del pasado es Una Lima que se va (1921)', con la que el cronista José Gálvez inaugura el tema de la vieja Lima como Arcadia Colonial en proceso de desaparición. El siguiente fragmento es sin duda muy significativo en este sentido:

...vino la guerra y con la guerra la miseria. Por eso los niños de las épocas inmediatamente posteriores a ella, alimentamos nuestro espíritu con la paradoja del relato fantástico de pasadas opulencias, contrastando con la dolorosa y miserable realidad presente. La mentira convencional de la grandeza pretérita llenó nuestros oídos juntamente con las lamentaciones y los anatemas por la guerra. [...]

La Lima anterior a 1895 se convirtió en una ciudad triste. Mis recuerdos de ella en aquel tiempo, tienen un dejo romántico y dolorido. Lo que se contaba de aquellos días de grandes bailes, de suntuosas tertulias, de elegantes paseos, parecía tan lejano que casi nos era ausente. Nuestros ojos veían el contraste amargo de la pobreza reinante. ${ }^{8}$

Según Sebastián Salazar Bondy, el mito de la tradición colonial, utilizado hasta el presente como instrumento para perpetuar un orden pasado de privilegios, tuvo como bastión esencial para el éxito el hecho de que, con contadas excepciones, «todos los escritores de Lima en el orden costumbrista tuvieron especial menosprecio por lo moderno y se jactaron de su veneración a los tiempos idos, sus gollerías y sus ocios», perspectiva que escondía «un parsimonioso antídoto contra el progreso: la moraleja conservadora»". Y añade que para el éxito de la Arcadia Colonial, el mundo de las letras, con todo su aparato universitario y académico, desempeñó un papel fundamental.

Sin embargo, durante las primeras décadas del siglo XX, algunos escritores comienzan a producir obras que se forjan sobre la realidad provinciana y citadina que hasta el momento había sido silenciada y sustituida por la recreación de un pasado que siempre parecía mejor. Pensemos en nombres como Abraham Valdelomar, Enrique López Albújar, César Vallejo, Martín Adán o José Díez-Canseco. Ahora bien, incluso en ciertas obras de algunos de estos escritores, el discurso de "la Lima que se va» continúa desarrollándose a través de una reelaboración del mito arcádico: las recuperaciones de la Lima colonial se sustituyen ahora por las reiteradas evocaciones de los balnearios limeños como últimos reductos en los que pervivía de algún modo el ambiente de la Lima antigua. Todavía en 1957 Luis Alayza evocará el balneario del Miraflores de los años 30 como «un rinconcito de la Arcadia por el sosiego de los últimos días del siglo XIX, siglo que se prolongará hasta muy entrado el actual» ${ }^{10}$.

Se forja así una tradición urbana desde principios de siglo que da continuidad al discurso idealizador del pasado, desde las evocaciones de Barranco realizadas por José María Eguren en algunos de sus poemas, Manuel Beingolea en Bajo las lilas (1923), Martín Adán en La casa de cartón (1928) o Díez-Canseco en Suzy (1930), hasta llegar a las recreaciones de Miraflores que encontramos en diversos relatos y capítulos de las novelas de Julio Ramón Ribeyro. Pero en el transcurrir de esta historia de la ciudad desvanecida, la realidad nacional cambia radicalmente $y$, con ella, se transforman los intereses de los escritores, cuyas evocaciones de la «Lima que se va» se convierten en la imagen ideal para la crítica y la denuncia de un presente conflictivo y problemáticamente modernizado. Tal es el caso de las evocaciones de Barranco en la obra de Díez-Canseco o la radical oposición entre este mismo balneario y el centro de $\mathrm{Li}$ -
7 José Gálvez, Una Lima que se va, Lima, Euforión, 1921.

8

Ibidem, págs. 238-239.

9

Sebastián Salazar Bondy, Lima la horrible, México, Era, 1968, págs. 92-93.

10

Luis Alayza y Paz Soldán, «Miraflores. Impresiones retrospectivas», Fanal, vol. XIII, n 50 (1957), pág. 6.

Evocaciones de la arcadia colonial en la literatura peruana: de Ricardo Palma a Julio Ramón Ribeyro EVA Ma VALERO JUAN 


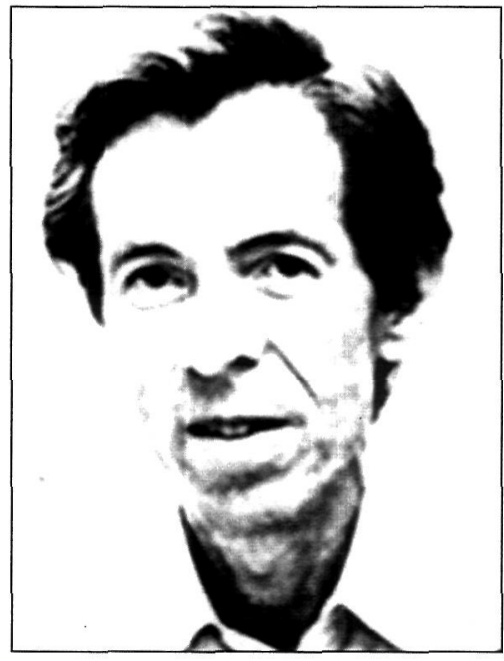

Julio Ramón Ribeyro

11

José Díez-Canseco, Suzy, págs. 37-38. Cit. en la introducción de Jorge Aguilar Mora a Martín Adán. El más hermoso crepúsculo del mundo (antología), México, Fondo de Cultura Económica, 1992, pág. 20.

12

La primera referencia a «Lima la horrible» aparece en el poema de César Moro "Viaje hacia la noche», de La tortuga ecuestre.

Evocaciones de la arcadia colonial en la literatura peruana: de Ricardo Palma a Julio Ramón Ribeyro EVA $M^{a}$ VALERO JUAN ma en La casa de cartón de Martín Adán. Recordemos, por ejemplo, la siguiente evocación de Díez-Canseco en su novela $S_{u z y}$, en la que el balneario de Barranco aparece descrito con reminiscencias de la antigua ciudad colonial:

Barranco: solaneros vestíbulos inmensos guardados por altas rejas; festoneados de helechos de altas macetas suspendidos; con hamacas coloridas; con tarjeteros de pajas japonesas [...] Barranco; paz calurosa de vacaciones marinas, en que canta la somnolencia de las campanitas de la iglesuca que rige clérigo beato y sacristán celestino [...] $\mathrm{Ba}$ rranco: desiertas callejas por las que discurren pesadas carretas, alígeras carretas, levantando con el restallar de los látigos el vuelo de las palomas que cantan sotto-voce: currucucú [...] Jacarandás que tejen lilas alfombras entre las bancas de la tarde romántica [...] Parque undoso con la brisa que remueve sebes rojizas, verduzcas, grises [...] Aroma de algas, de lluvia de acequias parleras que dan de beber a los sauces santurrones de este pueblo santurrón, también, y beato ${ }^{11}$.

Este discurso idealizador del pasado alcanza por tanto la mitad del siglo XX, momento principal de la transformación urbana, en el que las últimas imágenes del pasado bucólico desaparecen ante la irrupción de la ciudad industrializada. Durante los años 40 y 50 la masiva migración de las provincias obligó a un crecimiento vertiginoso de la urbe, cada vez más desbordada tanto en zonas residenciales como en la formación de las barriadas o «pueblos jóvenes» en las faldas de los cerros. «La ciudad de la gracia», como la denominó Rubén Darío, se cubre de gris y se transforma en su opuesto, adquiriendo ese apelativo que Sebastián Salazar Bondy fijó al escribir el ensayo Lima la horrible ${ }^{12}$. No es de extrañar que los escritores que trazaron la imagen de esta última, utilizaran las gracias de la primera como contraste y vía para la percepción problematizada del cambio.

La opulenta Ciudad de los Reyes asiste por fin a la nacionalización de su espacio. El proceso de la literatura peruana había mitificado un pasado quimérico de paz y felicidad en las obras que registran la desintegración de la Lima virreinal -Enrique Carrillo, José Gálvez, Luis Alayza, etc.-; el mismo pasado que
Manuel González Prada, José Carlos Mariátegui y Sebastián Salazar Bondy denunciaron como causa directa de la pervivencia del sistema clasista y de los problemas globales de un país aletargado. A mediados de siglo, la transformación urbana impone una fisonomía totalmente renovada a la ciudad, clausura la ya tambaleante exclusividad limeña e incorpora a su espacio la imagen del país real. Esta apremiante realidad demandaba una nueva literatura en la que figurara un presente histórico problemático y complejo.

El advenimiento de la industria y la afluencia incontrolada de habitantes de las provincias a la capital durante los años 40 y 50 transformaron la ciudad y, de manera simultánea, nació una literatura disidente con la tradición edulcorada y mitificadora de la Arcadia Colonial -la expresión más rotunda se encuentra en Lima la horrible de Salazar Bondy-. La ciudad, por fin descrita en su integridad, y como imagen de la realidad nacional, muestra a partir de este momento las contradicciones que se derivan de un proceso modernizador aplicado sobre las bases de una sociedad tradicional y adormecida.

Los escritores de la generación del 50 -la generación del neorrealismo urbano, (cuyos nombres principales son Enrique Congrains Martín, Oswaldo Reynoso, Eleodoro Vargas Vicuña, Carlos Eduardo Zavaleta, Luis Loayza, Sebastián Salazar Bondy y Julio Ramón Ribeyro)- ponen sus novedosos acentos sobre la inédita realidad urbana de mediados de siglo a través de una perspectiva crítica y analítica de las aceleradas transformaciones urbanas. Pero incluso algunos de ellos, y en especial Julio Ramón Ribeyro, recuperan esporádicamente el balneario idílico de su infancia como medio de contraste para el retrato de una realidad desencantada y marginal. $Y$ es así como a través de estas evocaciones perpetúan, si bien con un objetivo distinto, la tradición de «una Lima que se va».

Sin duda, en Ribeyro la percepción nostálgica del pasado limeño está presente en sus cuentos urbanos y marca su aprehensión de la ciudad, característica que nos induce a situarlo en dicha tradición. Pero en su escritura esta evocación responde a una utilización mediatizada, es decir, el escritor la utiliza como recurso o mecanismo de crítica; en definitiva, Ribeyro alude en sus cuentos a un viejo orden con el fin de contraponerlo con el presente y 
fundar en su narrativa la Lima que por estos años experimenta una acelerada transformación. Por ejemplo, en el siguiente fragmento del cuento de Ribeyro «Dirección equivocada»:

No pasaba un día sin que cayera un solar de la colonia, un balcón de madera tallada o simplemente una de esas apacibles quintas republicanas, donde antaño se fraguó más de una revolución. Por todo sitio se levantaban altivos edificios impersonales, iguales a los que babia en cien ciudades del mundo. Lima, la adorable Lima de adobe y de madera, se iba convirtiendo en una especie de cuartel de concreto armado. La poca poesía que quedaba se había refugiado en las plazoletas abandonadas, en una que otra iglesia y en la veintena de casonas principescas, donde viejas familias languidecían entre pergaminos y amarillentos daguerrotipos ${ }^{13}$.

El sueño de la edad dorada se desvanece en esta segunda fundación literaria de Lima, al establecer una perspectiva crítica y analítica de las aceleradas transformaciones urbanas acaecidas durante estas décadas. Toda la instrumentalización mitificadora de la Arcadia Colonial y sus privilegios, en aquella literatura pasatista que no hacía sino remarcar la abisal fisura social del Perú, al eludir y silenciar a la población desfavorecida y mayoritaria, servía para afianzar el privilegio de las clases dominantes. Sin embargo, en la obra de estos escritores se pone al descubierto el desarraigo que sufren esos habitantes silenciados o mudos $^{14}$ que han renovado el paisaje humano de la ciudad.

La secuencia viva de la literatura peruana se sustenta por tanto en la persistente recuperación de determinados aspectos del mundo colonial y, en general, en la evocación melancólica y nostálgica del pasado como valor omnipresente que se encuentra ya en la propia fundación del discurso peruano, es decir, en la obra del Inca Garcilaso.

En el proceso de formación de la nación peruana, el arraigado tradicionalismo de las dos culturas en contacto se consolidó como valor indispensable de la idiosincrasia nacional. Al profundo tradicionalismo de la cultura indígena que, transida de una profunda nostalgia, veneraba el pasado legendario, vino a unirse el recio tradicionalismo castizo de los españoles $\mathrm{y}$, tras la independencia, la cultura criolla reivindicó la tradición colonial que pervivía en todas las formas sociales y culturales de la vida peruana. En este sentido, Porras Ba- rrenechea considera el tradicionalismo como rasgo consubstancial de la cultura peruana en su expresión tanto colonial como indigenista:

Garcilaso, Palma, Chocano representan ese anhelo evocativo contaminado de las utopías de las edades de oro y esa angustia de inmortalidad consubstancial del alma ibérica. Las persistentes corrientes colonialistas de nuestra literatura y del arte arquitectónico, el culto de las tradiciones hispánicas tan arraigado en Lima, así como las nuevas corrientes incanistas e indigenistas, que son expresión de un pasadismo aún más exacerbado y reversido, son prueba de este anhelo peruano de eternizar su propia huella, de vencer al azar y a la circunstancia, con la perpetuación de los mismos ritos ancestrales y de las mismas formas de vida, a fin de conservar intacto el oro de la grandeza antigua que sólo con el correr del tiempo adquiere la pátina de un blasón. Por eso son $\tan$ genuinas y tan peruanas las Tradiciones de Palma ${ }^{15}$.

Pero la secuencia viva de la literatura peruana también se sustenta en otra forma de recuperación, como es el proceso intertextual que continúa desarrollándose mediante la utilización de algunas tradiciones de Palma por parte de diversos autores para recuperar el mundo colonial. Al igual que Ricardo Palma reformuló textos del Inca y de otros autores de la Colonia en algunas de sus tradiciones, escritores posteriores utilizan algunas tradiciones de Palma en su recuperación de la colonia. Así, por ejemplo, en Una Lima que se va José Gálvez alude reiterada y explícitamente a Palma como fuente principal de sus cuadros de costumbres: «dice don Ricardo Palma», "según relata don Ricardo Palma»16, etc. $\mathrm{O}$, posteriormente, Ribeyro reelabora la tradición de Palma titulada «Santiago el Volador» en su obra teatral «Santiago, el pajarero», que recibió el Premio Nacional en 1959.

En su tradición, ubicada en la Lima del siglo XVIII durante el gobierno del Virrey Amat, Palma relata la historia de Santiago de Cárdenas, quien se propuso llevar a cabo el portentoso proyecto de volar como los cóndores, un sueño que le valió el escarnio general de su pueblo y la humillación de las autoridades. Ironías de la historia, su memoria como personaje popular pervivió en los esce-
13

Julio Ramón Ribeyro, Cuentos completos, Madrid, Alfaguara, 1994, pág. 169

14

Tomamos el término del título que reúne los cuentos completos de Ribeyro: La palabra del mudo.

15

Raúl Porras Barrenechea, El sentido tradicional de la literatura peruana, ed. cit., pág. 107.

16

José Gálvez, Una Lima que se va, Lima, Euforión, 1921, pág. 17.

Evocaciones de la arcadia colonial en la literatura peruana: de Ricardo Palma a Julio Ramón Ribeyro EVA Ma VALERO JUAN 

dor', en Tradiciones peruanas, Barcelona, Montaner y Simón Editores, 1894, tomo III, pág. 122

18

Julio Ramón Ribeyro, "Santiago, el pajarero", en Teatro, Lima, Instituto Nacional de Cultura, 1975, pág. 40.

19

Julio Ramón Ribeyro, «Gracias, viejo socarrón», art. cit., págs. 130-131.
Evocaciones de la arcadia colonial en la literatura peruana: de Ricardo Palma a Julio Ramón Ribeyro EVA M* VALERO JUAN narios de títeres de la Lima decimonónica. Así concluye Palma su entrañable historia:

Concluyamos. Santiago de Cárdenas aspiró a inmortalizarse, realizando acaso el más portentoso de los descubrimientos, y, jmiseria humana!, su nombre vive sólo en los fastos titiritescos de Lima.

Hasta después de muerto lo persigue la rechifla popular.

El destino tiene ironías atroces ${ }^{17}$.

El relato de Palma, pretendidamente objetivado en documentos fidedignos y salpicado a la vez de especulaciones sobre los posibles sucesos acaecidos a su protagonista, es reformulado en la obra de Ribeyro conforme al interés del escritor que, recuperando un suceso histórico y reconstruyendo el ambiente de la Lima dieciochesca, consigue realizar una crítica al dogmatismo histórico y a las injusticias seculares que perviven en el mundo contemporáneo.

Desde este punto de vista novedoso en su obra global, la recuperación del universo colonial le sirve como acicate para agudizar la crítica de un mundo contemporáneo que arrastra el pesado lastre de la historia de la colonia. Ribeyro da vida al sistema clasista mediante la representación de una sociedad jerarquizada y conservadora, en la que priman la apariencia y el valor del dinero. Dentro de esa sociedad figuran los artistas, excéntricos y marginados del orden social. Entre ellos, Santiago representa, con su proyecto de volar, la libertad, el espíritu creador, la posibilidad de la duda y de la investigación, frente al academicismo postrado de los insignes doctores de la Universidad de San Marcos.

La obra proyecta por tanto la lucha entre los intereses pragmáticos y económicos y el espíritu creador y desinteresado del artista. En este cuadro social de la Lima perricholesca hay que llamar la atención sobre la actitud del pueblo que, sometido a los intereses del virreinato, acata sus valores y demuestra en todo momento su reticencia a los brotes de individualismo creador o a cualquier atisbo de diferencia con respecto a los intereses de la masa. En las palabras del virrey se encuentra la clave de la solidez del sistema clasista: «Mi querido pueblo resiste todo. Le daremos espectáculos y algún buen escándalo que entretenga sus pasiones y apacigüe su humor» ${ }^{18}$.

En definitiva, en el drama histórico Santiago, el pajarero se encuentran las claves de la percepción urbana y la intencionalidad literaria de Ribeyro: partiendo de la ciudad como lugar donde se manifiesta el diálogo social, el escritor encuentra un espacio para la crítica y la sátira de un orden consensuado y establecido por el poder oficial $y$, desde ese espacio, proyecta el drama de los seres que habitan en sus páginas, esto es, la caída final del sueño o la ilusión en la oprimente y mediocre realidad.

Llegamos así, por este camino que traza la percepción de Lima en la historia de la literatura peruana, desde Palma hasta Ribeyro. En el citado artículo «Gracias, viejo socarrón», Ribeyro reconocía en la obra de Palma no sólo la herencia, sino el desafío para la construcción de una nueva imagen de Lima que, adecuándose a los tiempos, representara el reemplazo de la Arcadia colonial por la urbe contemporánea en la dimensión imaginaria de la escritura:

Para concluir, volvamos pues a nuestro viejecito, que abandonamos achacoso en una alameda de Miraflores. En el curso de esta nueva digresión ya se murió. Se fue a la tumba dejándonos (iba a decir un clavo, pero me parece vulgar), dejándonos un desafío y, para ser más justos, una herencia. Como Moisés salvado de las aguas, cumplió para con su pueblo una misión histórica. No nos llevó seguramente a la Tierra Prometida, pero nos brindó para colmar nuestra orfandad, una tierra imaginaria ${ }^{19}$.

Partiendo de esta tradición urbana que enlaza a Palma con Ribeyro, quiero concluir reparando en el hecho de que el discurso mitificador de un pasado idílico siempre se proyecta desde la recuperación de la infancia: al igual que el Inca recobra su infancia a través de la creación en la que inventa la versión mítica de los Incas y su gran Imperio de paz y prosperidad, Palma recupera una Lima colonial cuyos rezagos ha alcanzado a vivir en su niñez, José Gálvez evoca su infancia en la Lima encantadora que compara con la decadencia y la pobreza de la posguerra, Martín Adán, Manuel Beingolea y Díez-Canseco proyectan el Barranco sereno de su infancia, Luis Alayza y Ribeyro tratan de apresar las imágenes desvanecidas del Miraflores arcádico que disfrutaron de niños, etc.

Desde esta percepción, la tradición mitificadora del espacio limeño adquiere unos rasgos básicos, principalmente la escritura 
de una versión mítica e idealizadora del pasado, la construcción de dicho discurso a través de la recuperación de la infancia en la creación y, por último, la ficcionalización de un discurso que dramatiza los cambios e impone el contraste con el presente. Este discurso se encuentra ya en Palma y llega hasta Ribeyro:

Lima ha ganado en civilización; pero se ha despoetizado y día a día pierde todo lo que de original y típico hubo en sus costumbres. (Ricardo Palma: «Con días y oilas venceremos» $)^{20}$

El país se había transformado y se seguía transformando y Lima, en particular, había dejado de ser el bortus clausum virreinal para convertirse en una urbe ruidosa, feísima e industrializada, donde lo más raro que se podía encontrar era un limeño. (J. R. Ribeyro: «El marqués y los gavilanes» $)^{21}$

Entre ambos escritores principales de la tradición literaria limeña, una larga serie de narradores ha sustentado este discurso a tra- vés de la recuperación de la Lima colonial. En el transcurso del siglo XX, los escritores encuentran en el balneario edénico de la infancia una remembranza de la apacible ciudad colonial y, en sus evocaciones, reelaboran el mito arcádico y dan continuidad al discurso que registra los cambios. Discurso cuyo objetivo literario ya no está en la Lima de ayer sino en la denuncia del orden social establecido y consensuado en la ciudad contemporánea.

El eje de esta tradición se desarrolla en el período que separa las dos fundaciones literarias de la ciudad. Entre la fundación de la ciudad mitica por Ricardo Palma y la de la ciudad mestiza por Ribeyro, o si se prefiere, entre la creación literaria de la ciudad colonial -la Ciudad de los Reyes-y la creación de la ciudad industrial -«Lima, la horrible»-, la tradición de «una Lima que se va» evoluciona desde su funcionalidad para la creación de la leyenda urbana hasta su utilización para la disolución del mito en el seno de la Lima transformada.
20

Ricardo Palma, Tradiciones Per ruanas, Barcelona, Montaner $y$ Simón, 1893, tomo l, pág. 387. 21 Cuentos completos, ed. cit., pág. 467.
Evocaciones de la arcadia colonial en la literatura peruana: de Ricardo Palma a Julio Ramón Ribeyro EVA $M^{2}$ VALERO JUAN 